\title{
Stress intensity factors analyses for external semi-elliptical crack for repaired gas-pipeline by composite overwrap under pressure
}

\author{
D. E. Belhadri, M. Belhamiani, W. N, Bouzitouna, W. Oudad \\ Smart Structures Laboratory Univ Ctr of Ain Témouchent, Po Box 284,46000, Algeria \\ djamelins@hotmail.fr,mbelhamiani@gmail.com, bibanesrine@outlook.fr \\ oudadw@gmail.com, bttps://orcid.org/0000-0002-3283-1322
}

\begin{abstract}
The purpose of this article is to present the stress intensity factors (SIF) solutions for semi-elliptic crack in pipelines under internal pressures, the stress intensity factors are calculated by the three-dimensional finite element method (FEM) for cracked pipelines and repaired pipe by composite patch. The distribution of normalized stress intensity factors $\left(\mathrm{K}_{\mathrm{I}}, \mathrm{K}_{\mathrm{II}}\right.$ and $\left.\mathrm{K}_{\mathrm{III}}\right)$ along the crack front for different crack lengths, crack depth, crack geometry, lap length and composite thickness was obtained by nodal calculations. Our results show the presence of three failure modes along the semi elliptical crack front and has three zones in which the stress intensity factor in mixed mode $\left(\mathrm{K}_{\mathrm{II}}\right)$ the higher-values comparing to $\mathrm{K}_{\mathrm{I}}$ and $\mathrm{K}_{\mathrm{III}}$. It can also be noted that the composite repair reduces the SIF $\mathrm{K}_{\mathrm{I}}$ by $46 \%$ and the $\mathrm{K}_{\mathrm{II}}$ by $55 \%$ and the $\mathrm{K}_{\mathrm{III}}$ by $72 \%$ near the outside diameter of the pipe in each zone. However, the reduction of the SIF $K_{I}$ is more significant for the rectangular crack than for the semi-elliptic crack, from which it is concluded that the composite repair is very effective for a rectangular crack with respect to the semi-elliptic crack. Thereby, the fracture behavior of the semi-elliptic crack is governed by the three modes of failure and not only by mode I.
\end{abstract}

KEYwORDS. Stress intensity factor; Crack; Composite; Adhesive; Pipeline, API 5L X65.

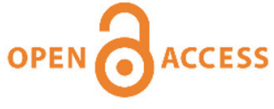

Citation: Belhadri, D. E, Belhamiani, M., Bouzitouna, W. N., Oudad, W., Stress intensity factors analyses for external semielliptical crack for repaired gas-pipeline by composite overwrap under pressure, Frattura ed Integrità Strutturale, 49 (2019) 599-613.

Received: 21.01.2019

Accepted: 09.05.2019

Published: 01.07.2019

Copyright: (C) 2019 This is an open access article under the terms of the CC-BY 4.0, which permits unrestricted use, distribution, and reproduction in any medium, provided the original author and source are credited.

\section{INTRODUCTION}

A round the world, more than 1.7 million kilometers of pipeline are used to transport gas, crude oil and petroleum products [1]. Many of these pipelines have been in service since the 1940s and 1950s [2]. Therefore, each year between 2 and 3.3 billion $\$$ dollars in the US alone is lost to corrosion in the gas and oil pipelines that need to be repaired or replaced. [3] The large amount of external corrosion of pipeline increases ultimately the cost of energy. Faced with the phenomena of ruins of structures or components with signs of rupture, the industry has to offer effective solutions to enhance or prolong the life of the damaged structure or even valued the equipment [4].

The composite repairs were used in the transmission pipeline industry for the past 20 years for the repair and strengthening of permanent sections of the tube wall that have been weakened due to corrosion. [5] Most repair codes internationally 
recognized, such as ASME B31.4 [6] and B31.8 [7], accept the use of composite materials for the repair function. Most oil and gas pipeline operators are familiar with composites and the health, safety, technical and commercial benefits they provide.

Composite repairs are a proven and accepted technology for repairing high pressure pipelines. For example, Clock Spring has completed more than 100,000 repairs in more than 62 countries around the world [5]. Pipeline defects can be permanently repaired using composites technology in a safer, faster and cheaper way than any other technique.

C. Alexander and B. Francini [8] had developed a detailed state of the art assessment of composite systems used to repair transmission pipelines. Many researches had used the stress intensity factor as a criterion to evaluate the efficiency of the composite repair system. Many crack configurations are used to calculate the SIF such as the rectangular and the semi elliptical crack. Newman and Raju (1984) [9] detailed an analytical study of the stress intensity factor equations for an embedded elliptical crack, a semi elliptical surface crack, a quarter-elliptical corner crack, a semi elliptical surface. crack along the bore of a circular hole and a quarter elliptical corner crack at the edge of a circular hole in finite plate. The equations give stress intensity factor as a function of parametric angle, crack depth, crack length, plate thickness, and where applicable, hole radius. A. Saffih and S. Hariri studied elliptical cracks in a cylinder with a thickness transition. They found that SIF calculations in the transition, assuming a uniform thickness cylinder are conservative but not precise. The comparative study shows that the cylinder with a thickness transition is more vulnerable to a defect [10]. Another study of the U.S. Department of Transportation presents an investigation to determine the mode I stress-intensity factors, along two symmetric surface cracks emanating from a centrally located hole in a rectangular plate using the domain integral method [11]. Excellent agreement was obtained with those of Newman and Raju (1983).

All these researches are focused on the study of the behavior in rupture in opening mode (mode I). The objective of the present work is to highlight the behavior of a semi-elliptic crack governed by the three failure modes in pipe subjected to internal pressure, after that the study extends on the estimation of the efficiency of repair of the pipe by a carbon-epoxy composite.

\section{STRESS INTENSITY FACTORS CALCULATION}

$\mathrm{T}$ he stress intensity factor (SIF) is one of the most important parameters in fracture mechanics. Brittle fracture in cracked engineering components is usually examined by SIF. After the crack detection in a structure, SIF can be calculated by various experimental or theoretical methods such as finite element analysis. Once SIF is known the risk of brittle fracture can be evaluated by using an appropriate fracture criterion. The mode I and mode II stress intensity factors $\left(\mathrm{K}_{\mathrm{I}}\right.$ and $\left.\mathrm{K}_{\mathrm{II}}\right)$ can be calculated from finite element analysis based on the displacement functions ( $\mathrm{u}$ and $\mathrm{v}$ ) in a local coordinate system fixed to the crack tip [12] .

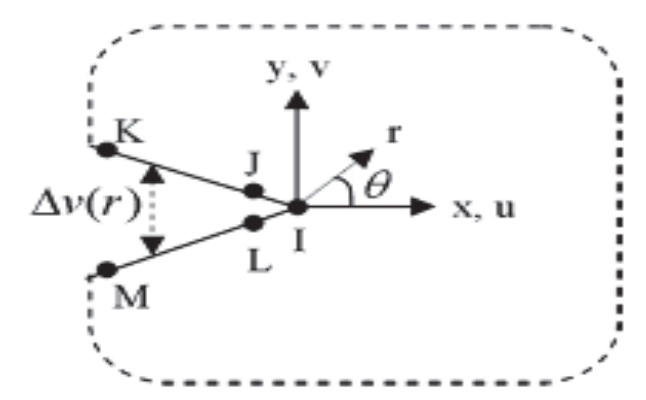

Figure 1: Local Cartesian coordinates on crack tip.

$$
\begin{aligned}
& K_{I}=\sqrt{2 \pi} \frac{2 G}{1+k} \frac{\Delta v(r)}{\sqrt{r}} \\
& K_{I I}=\sqrt{2 \pi} \frac{2 G}{1+k} \frac{\Delta u(r)}{\sqrt{r}}
\end{aligned}
$$

where $r$ is the radial distance from the crack front in the polar coordinates, $G$ is the shear modulus, $v$ is Poisson's ratio, and $\mathrm{k}$ can be defined for plane strain and plane stress problems as follows: 


$$
k= \begin{cases}3-4 v & \text { Plane strain } \\ 3 v /(1+v) & \text { Plane stress }\end{cases}
$$

For three dimensional models, different subscripts are used to designate the stress intensity factor for the three different modes. These factors are formally defined as [13]

$$
\begin{aligned}
& K_{I}=\lim _{r \rightarrow 0} \sqrt{2 \pi r} \sigma_{y y}(r, 0) \\
& K_{I I}=\lim _{r \rightarrow 0} \sqrt{2 \pi r} \sigma_{y x}(r, 0) \\
& K_{I I I}=\lim _{r \rightarrow 0} \sqrt{2 \pi r} \sigma_{y z}(r, 0)
\end{aligned}
$$

For cylinders subjected to axisymmetric loading, a decomposition of stresses in a polynomial form of third or fourth degree is usually used [14-18]. The SIF can be written in the form:

$$
K_{j}\left(\sigma_{j}\right)=\sigma_{j} i_{j}\left(\frac{a}{t}\right)^{j} \sqrt{\pi a} \quad j=1,2,3
$$

Recently an interesting study, published in 2018 has been proposed for rapidly estimating notch stress intensity factors using the singular linear elastic peak constraints named: peak stress method (PSM) [19,20].

\section{GEOMETRY AND LOADING OF CRACKED PIPE}

he pipe analyzed in this study is shown in Fig. 2 where $\mathrm{R}=350 \mathrm{~mm}, \mathrm{~L}$ is the longitudinal length $\mathrm{L}=1000 \mathrm{~mm}$, and $\mathrm{t}$ $=12.7 \mathrm{~mm}$ is the wall's thickness. The crack was repaired by using a glass-epoxy composite patch bonded cylinder form with an adhesive cylinder $e_{a d h}=02 \mathrm{~mm}, \mathrm{~L}_{\mathrm{adh}}=\mathrm{Lp}=100 \mathrm{~mm}, \mathrm{e}_{\mathrm{p}}=4 \mathrm{~mm}$. The end sections pipeline was subjected to no displacement in the longitudinal direction $(\mathrm{u} 3=0)$. The material properties of the pipeline, patch, and adhesive are summarized in Tab. 1. The pipe was made of X65 grade steel per API 5L PSL2 [21] specifications. The pipe is subjected to an internal pressure of $7 \mathrm{MPa}$. The material model is considered as an elastic material.

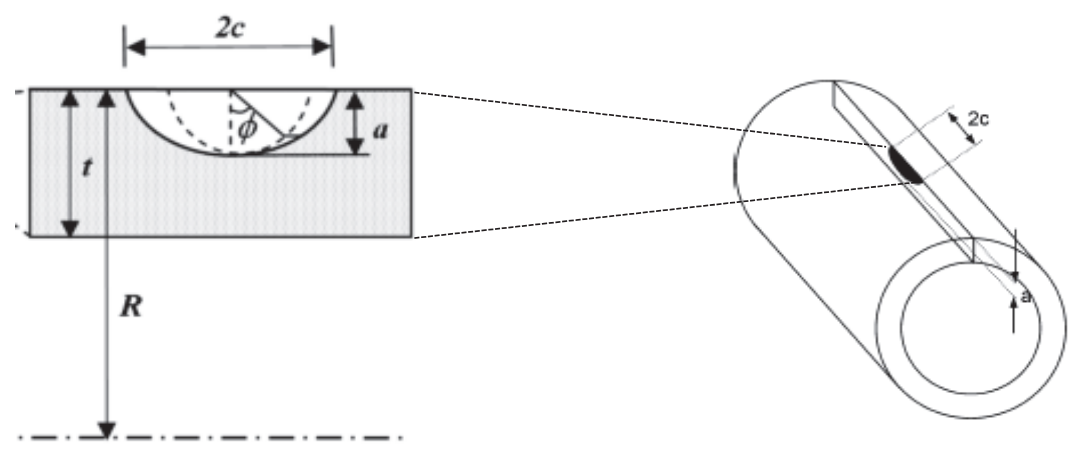

Figure 2: Geometry of the pipe with an external axial crack of semi-elliptical shape.

A range of ratios of a/t, c/t, patch length $\left(\mathrm{L}_{\mathrm{p}}\right)$, patch thickness(ep) as well as single and multi-laps of composite are highlighted in this study. 


\begin{tabular}{|c|c|}
\hline \multicolumn{2}{|c|}{ API 5L X65 properties [21] } \\
\hline Young's modulus $(\mathrm{GPa})$ & 205 \\
\hline Poisson's ratio & 0.3 \\
\hline Minimum yield stress (MPa) & 415 \\
\hline Yield strain & $0.5 \%$ \\
\hline \multicolumn{2}{|c|}{ Glass epoxy composite properties [22] } \\
\hline Young's modulus $\mathrm{E}_{1}(\mathrm{GPa})$ & 55 \\
\hline Young's modulus $\mathrm{E}_{2}, \mathrm{E}_{3}(\mathrm{GPa})$ & 15.2 \\
\hline Poisson's ratio $\cup_{12}, \mathrm{v}_{13}$ & 0.254 \\
\hline Poisson's ratio $\cup_{23}$ & 0.428 \\
\hline Shear modulus $\mathrm{G}_{12}, \mathrm{G}_{13}(\mathrm{GPa})$ & 4.7 \\
\hline Shear modulus $\mathrm{G}_{23}(\mathrm{GPa})$ & 3.28 \\
\hline \multicolumn{2}{|c|}{ Adhesive (FM73) properties [23] } \\
\hline Young's modulus (GPa) & 3.28 \\
\hline Poisson's ratio & 0.45 \\
\hline
\end{tabular}

Table 1: Material's properties.
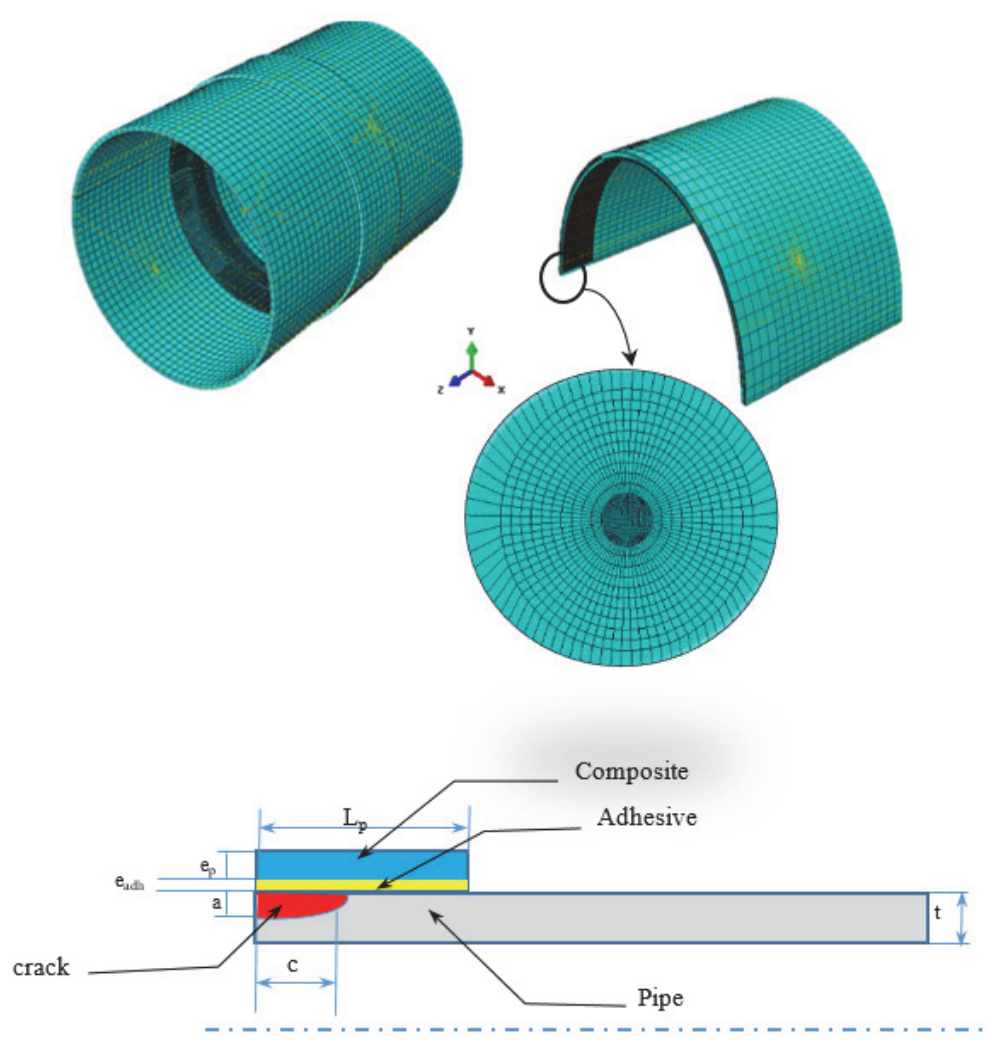

Figure. 3: Mesh type of the model and a geometry of the repaired pipe.

\section{FINITE ELEMENT MODELING}

$\mathrm{T}$

he cracked pipe was modeled using ABAQUS 6.14 [24], and meshed using a structured mesh with three-dimensional hex-dominated quadratic elements with a focused mesh surrounding the crack-tip of $0.02 \mathrm{~mm}$ element $[24,25,26$, 27, 28]. A meshed pipe is shown in Fig. 3. The reduced, C3D20R integration elements are used in this modelization to compute the stress intensity factors. Only a quarter of the specimen was modeled due to symmetry conditions. The procedure used in the finite element analysis involved the following steps: (i) the internal pressure was applied to the 
specimen; (ii) general static 'STEP'-option was used for analysis with ABAQUS; (iii) Automatic increment of steps was used with maximum increments number of 100. Minimum increment size was $10^{-5}$ and maximum increment size was 1 . Nevertheless, the ABAQUS solver code could override matrix solver choice according to the 'STEP'-option. The Von Mises yield criterion is used to predict plastic deformation. Incremental plasticity theory is introduced to model the material nonlinearity. The FE simulations are carried out using the static general procedure to analyze this problem.

\section{RESULTS AND DISCUSSION}

\section{A) Evaluation of the failure mode:}

In this part, we will focus on the crack failure. Fig. 4 presents the variation of the stress intensity factors in mode I, II, and III as a function of normalized line of the crack front for an unrepaired cracked pipe. We note that the behavior of the SIF is non-linear and that there are three areas. Zone 1 is influenced by shear mode II, which gives importance to circumferential stresses; in zone II, K1 has larger values than K2 and K3 until the end of the crack comes the appearance of mode III but of low intensity. We conclude that $75 \%$ of the crack front is controlled by mode II, $20 \%$ by mode I and only $5 \%$ of the crack front for mode III.

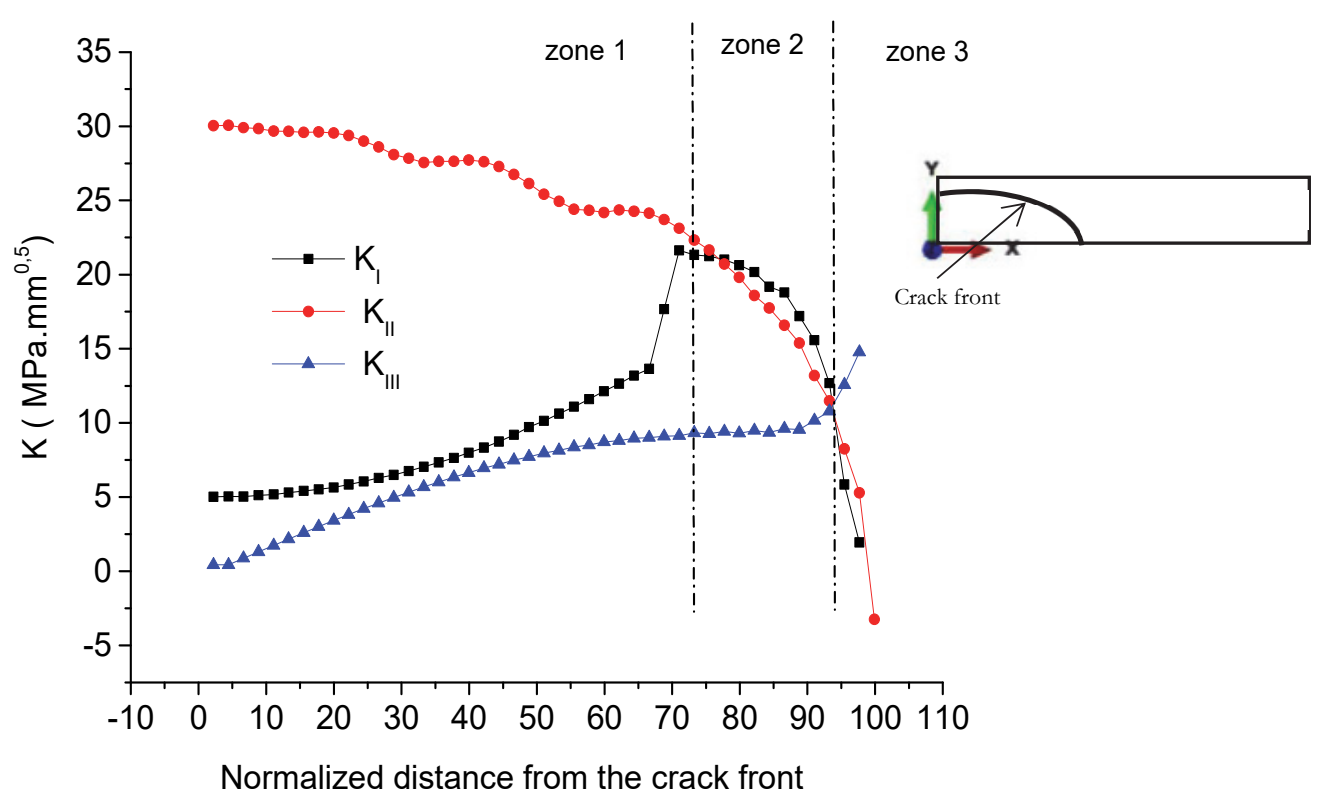

Figure 4: Variation of the SIF along the front of the elliptical crack for an unrepaired pipe $(\mathrm{c}=60 \mathrm{~mm}, \mathrm{a}=5 \mathrm{~mm})$.

In Fig. 4, composite repair does not change the configuration. Fig. 5 shows the variation of the SIF along the crack front for a repaired pipe fig 3, indeed the Zone 1 is still controlled by $K_{I I}$ but with more or less variable reductions for the three modes. To verify this reduction, each mode has been traced separately to quantify the rates of improvement knowing that these rates change from one crack to another.

In what follows we will use the variables $\mathrm{K}_{i}^{*}\left(\mathrm{SIF}^{*}\right)$, which will represent the improvement provided by the repair where:

$$
K_{i}^{*}=\frac{K_{i}^{\text {unrep }}-K_{i}^{r e p}}{K_{i}^{\text {unrep }}} \quad i=I, I I, I I I
$$

Fig. 6 (A) shows the distribution of the Mode I stress intensity factor along the crack front for a repaired and unrepaired pipe. There is a net reduction of the $K_{I}$ in the crack tip with a maximum of $46 \%$, this fall of the SIF decreases as the front touches the edge of the pipe. In Fig. 6 (B) is shown the effectiveness of the repair expressed by $\mathrm{K}^{*}$, the latter confirms the Fig. (A) since it is clear that the efficiency decreases towards the edge of the crack. 


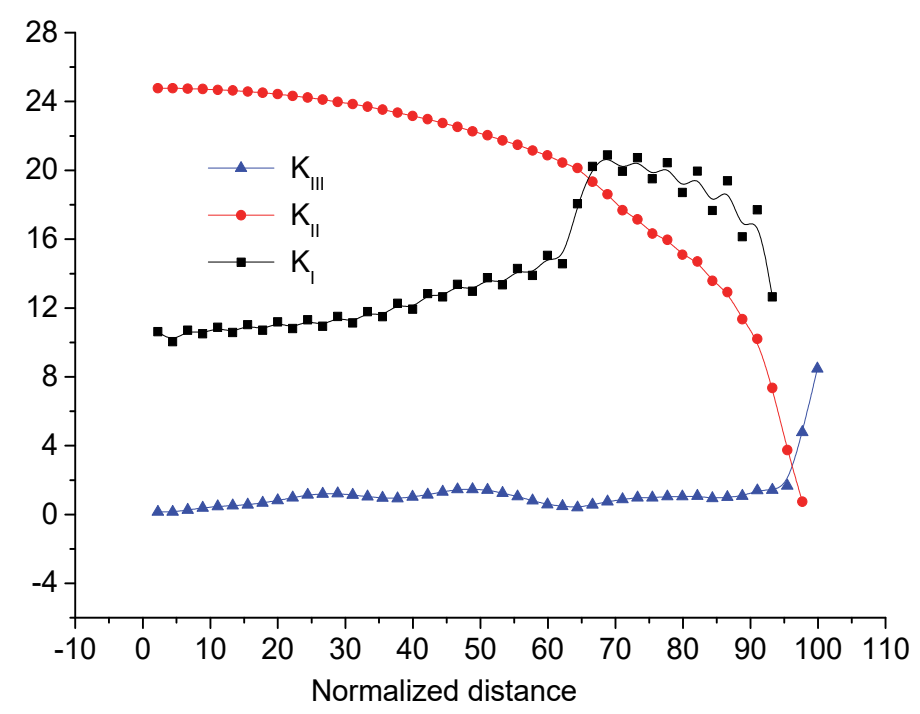

Figure 5: Variation of the SIF along the front of the elliptical crack for a repaired pipe $(\mathrm{c}=60 \mathrm{~mm}, \mathrm{a}=5 \mathrm{~mm})$.

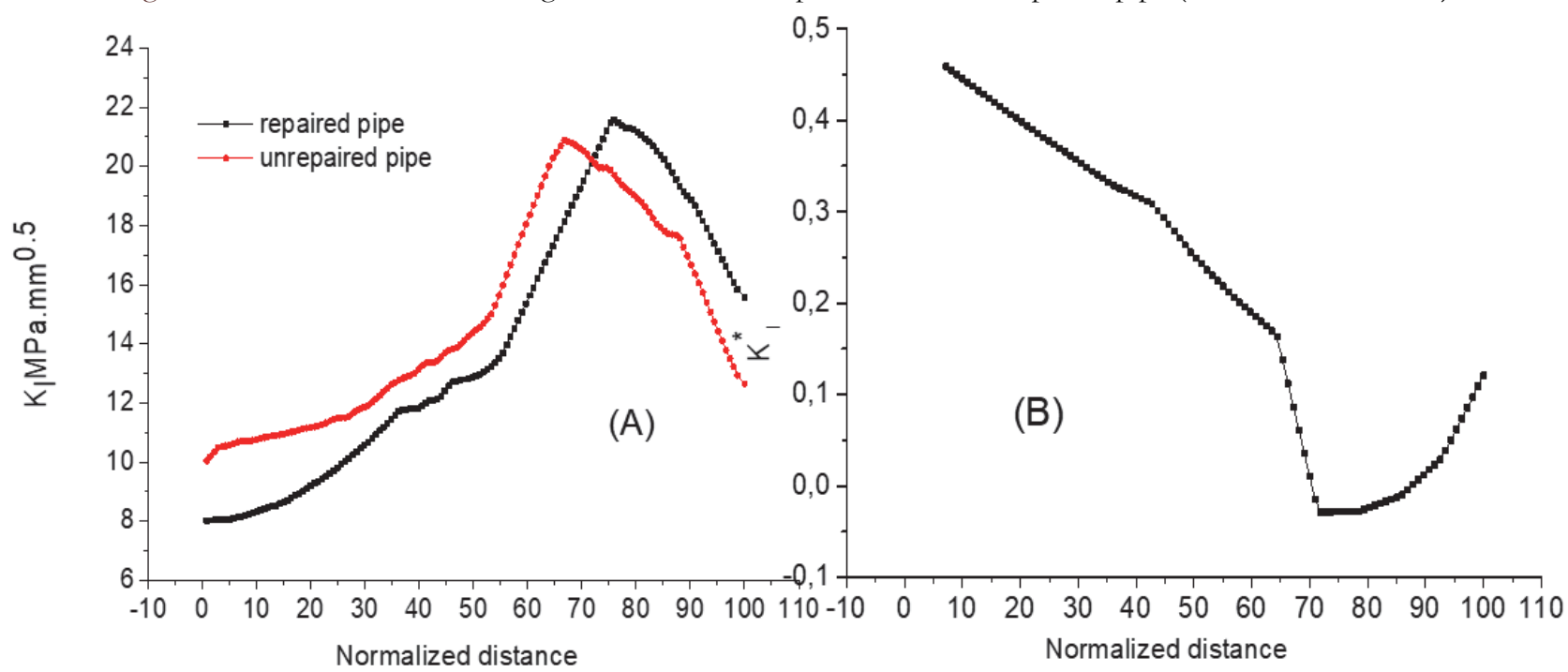

Figure 6: Variation of the SIF and $K_{I}^{*}$ along the front of the elliptical crack pipe $(c=60 \mathrm{~mm}, a=5 \mathrm{~mm})$.

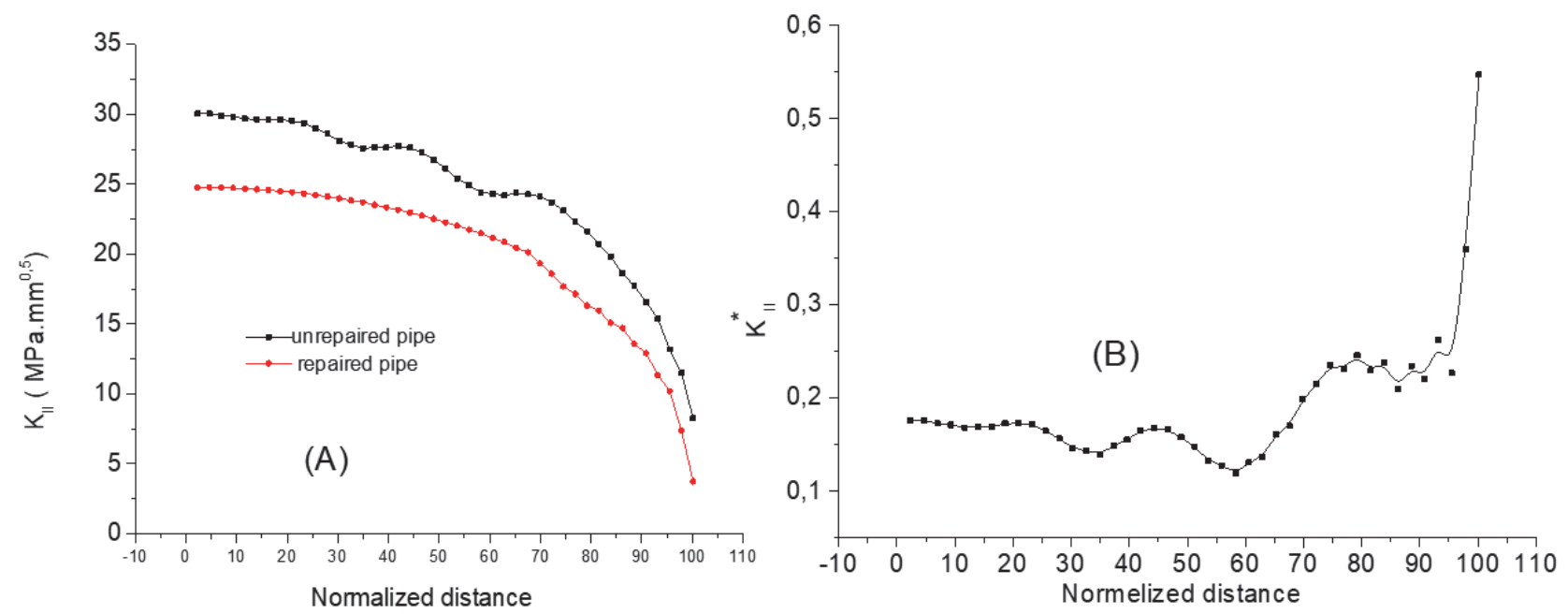

Figure 7: Variation of the SIF and $K_{I I}^{*}$ along the front of the elliptical crack pipe $(c=60 \mathrm{~mm}, \mathrm{a}=5 \mathrm{~mm})$. 
The $\mathrm{K}_{\mathrm{II}}$ variation on the crack front for a repaired and unrepaired pipe is shown in Fig. 7(A). It is visible that the composite repair also reduces the $\mathrm{K}_{I I}$ for a rate of only $17 \%$ for the median position of the elliptical crack. Conversely, at $\mathrm{K}_{I}^{*}$, the $\mathrm{K}_{I I}^{*}$ repair efficiency increases towards the extreme edge of the elliptical crack to reach $55 \%$. Fig. 7(B)

For $K_{\text {III }}$ Fig. 8 shows the variation of the $K_{\text {III }}$ along the crack front for a cracked pipe and a repaired pipe, it can be clearly seen that there is no effect of the repair at the bottom of the crack for the $\mathrm{K}_{\text {III }}$ on the other hand is approaching the end of the crack the effect of the repair is more marked with a reduced rate of $81 \%$.

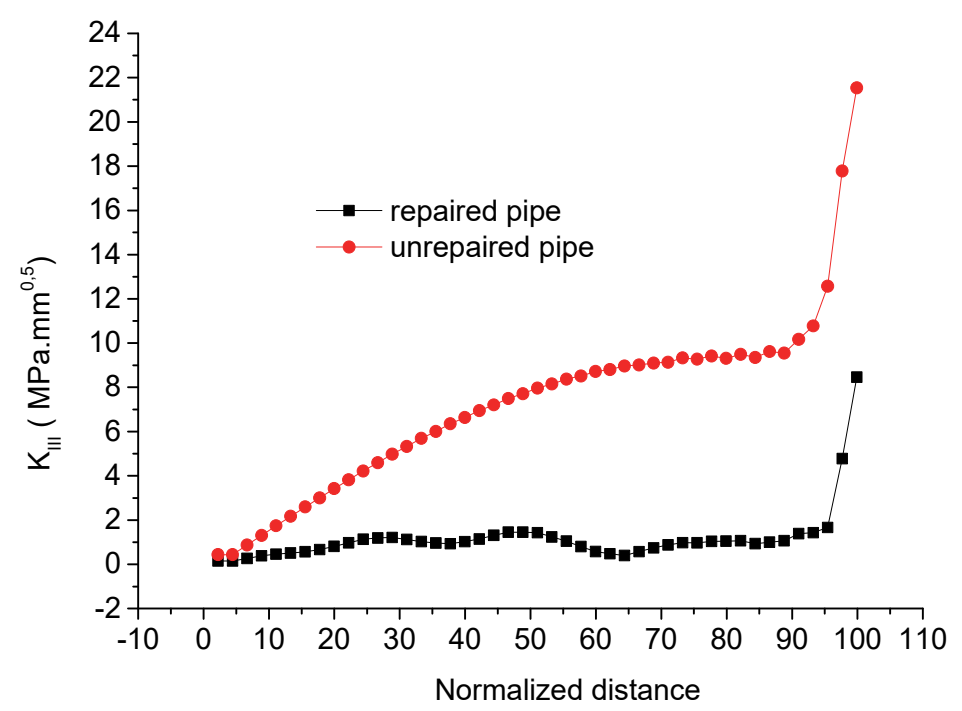

Figure 8: Variation of the $K_{I I I}$ along the front of the elliptical crack pipe $(c=60 \mathrm{~mm}, \mathrm{a}=5 \mathrm{~mm})$.

\section{B) Effect of the crack dimensions:}

The durability of composite patch repairs of damaged structures depends on the nature and size of the defects. The application of this technique will not be reliable if the size of the defect repaired exceeds a critical value. In this part, the effect of the crack size is represented by the crack progression in the thickness for the evaluation of the variation of the SIF.

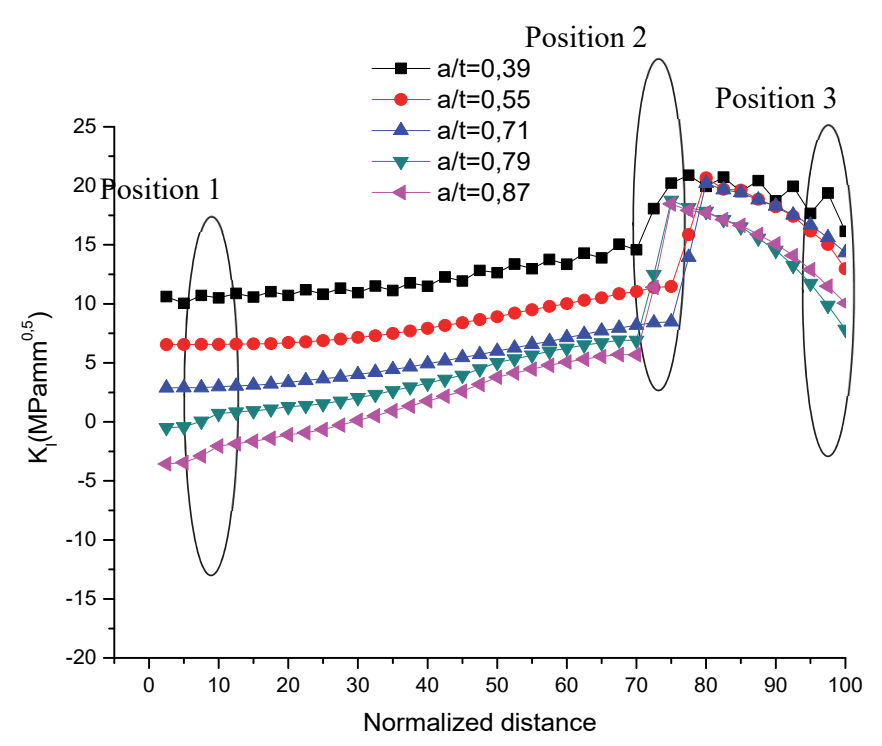

Figure 9: Variation of the $\mathrm{K}_{\mathrm{I}}$ along the front of the elliptical crack pipe for different crack depth $(\mathrm{c}=60 \mathrm{~mm})$. 
Fig. 9 shows the behavior of the $\mathrm{K}_{\mathrm{I}}$ along the crack front for different values of crack depth (a) and for a repaired pipe. We can say that the SIF keeps the same behavior regardless of the depth, but we also note that there are three areas as already mentioned before where there is a variation of the SIF and to illustrate this effect, we trace Fig. 10 to differentiate the variation of $K_{I}$ as a function of the depth (a) for the three zones noted in Fig. 9. The $K_{I}$ is inversely proportional to the depth (a) for the three positions, this is essentially due to the composite's behavior towards the deformation caused by the opening of the crack.; this confirms the beneficial effect of the composite repair even at $86 \%$ of the thickness of the pipe.

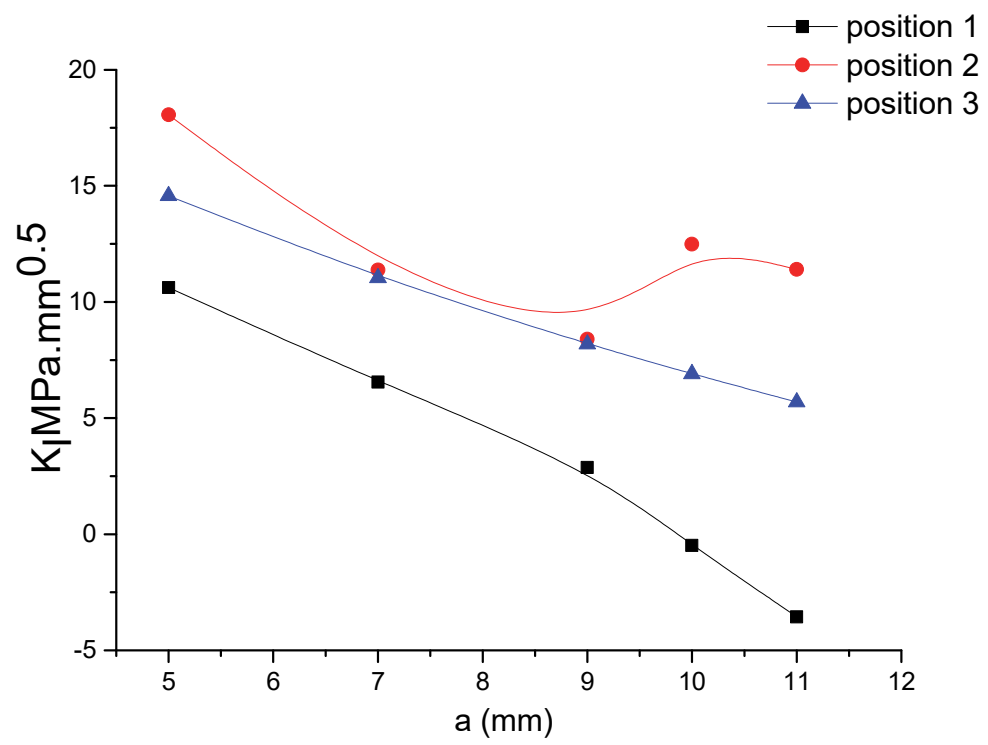

Figure 10: Variation of the $\mathrm{K}_{\mathrm{I}}$ along the front of the elliptical crack pipe for different crack depth in position $1,2 \mathrm{and} 3(\mathrm{c}=60 \mathrm{~mm})$.

Fig. 11 shows the variation of the $K_{I I}$ at the crack front as a function of the depth (a), the results show that the depth $\mathrm{a} / \mathrm{t}=0.87$ presents a major risk of rupture with a maximum value of $57 \mathrm{MPa} \mathrm{mm} \mathrm{m}^{0.5}$. This observation confirms that the failure behavior of the progress of the crack is more influenced by shear mode $\left(\mathrm{K}_{\mathrm{II}}\right)$ without neglecting the presence of the two other modes.

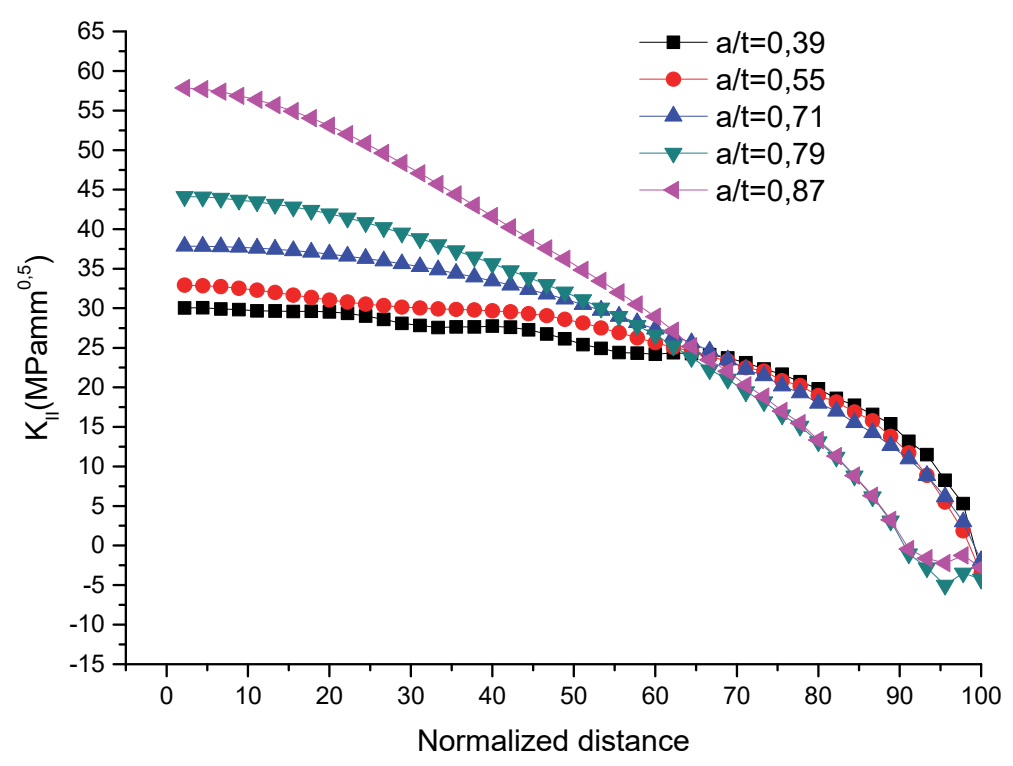

Figure 11: Variation of the $\mathrm{K}_{\mathrm{II}}$ along the front of the elliptical crack pipe for different crack depth $(\mathrm{c}=60 \mathrm{~mm})$. 
The behavior of the $\mathrm{K}_{\mathrm{III}}$ along the crack front is shown in Fig. 12 (A)for different values of (a). The median position of the crack is not sensitive to the variation of the $K_{I I I}$. On the other hand, and as already pointed out, this variation becomes more and more marked where $K_{I I I}$ progresses proportionally as a function of depth (a). Fig. 12 (B) asserts that $K_{I I I}$ reaches maximal values at the outer limit of the elliptical crack.
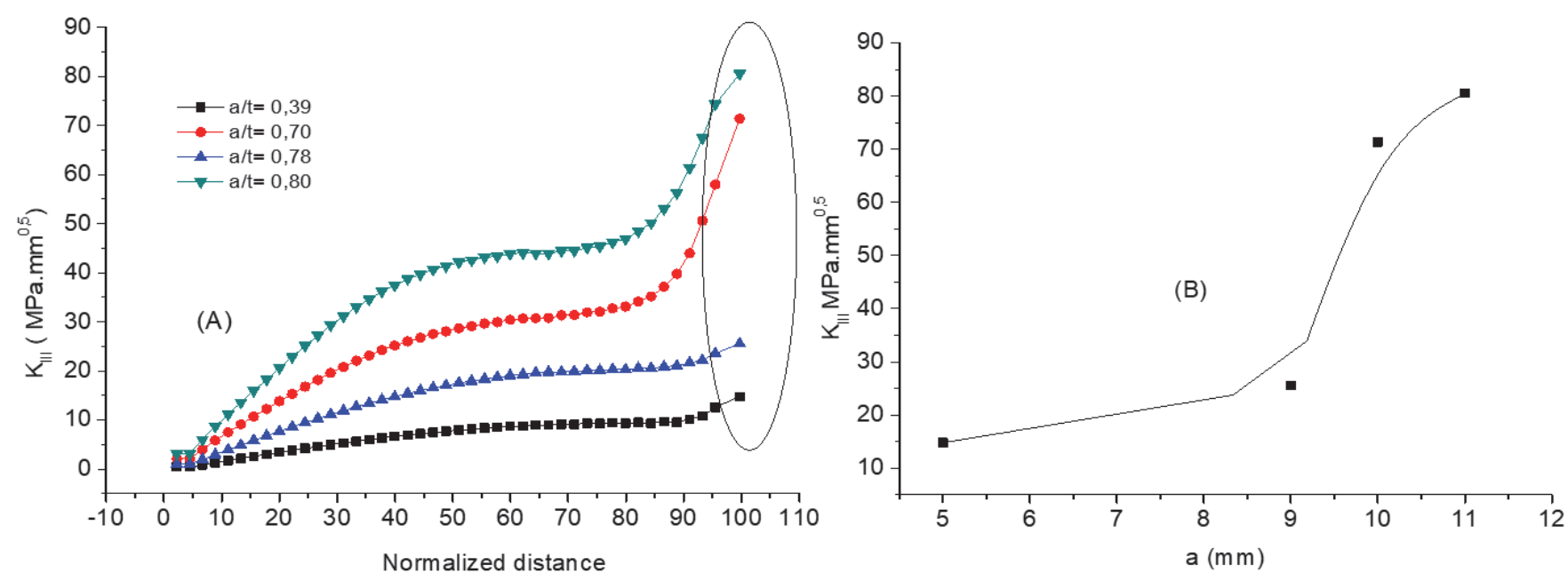

Figure 12: variation of $\mathrm{K}_{\mathrm{III}}$ along the front for different crack depth (A) variation of $\mathrm{K}_{\mathrm{III}}$ for position (4) of the crack (B). Repaired pipe with $\mathrm{c}=60 \mathrm{~mm}$.
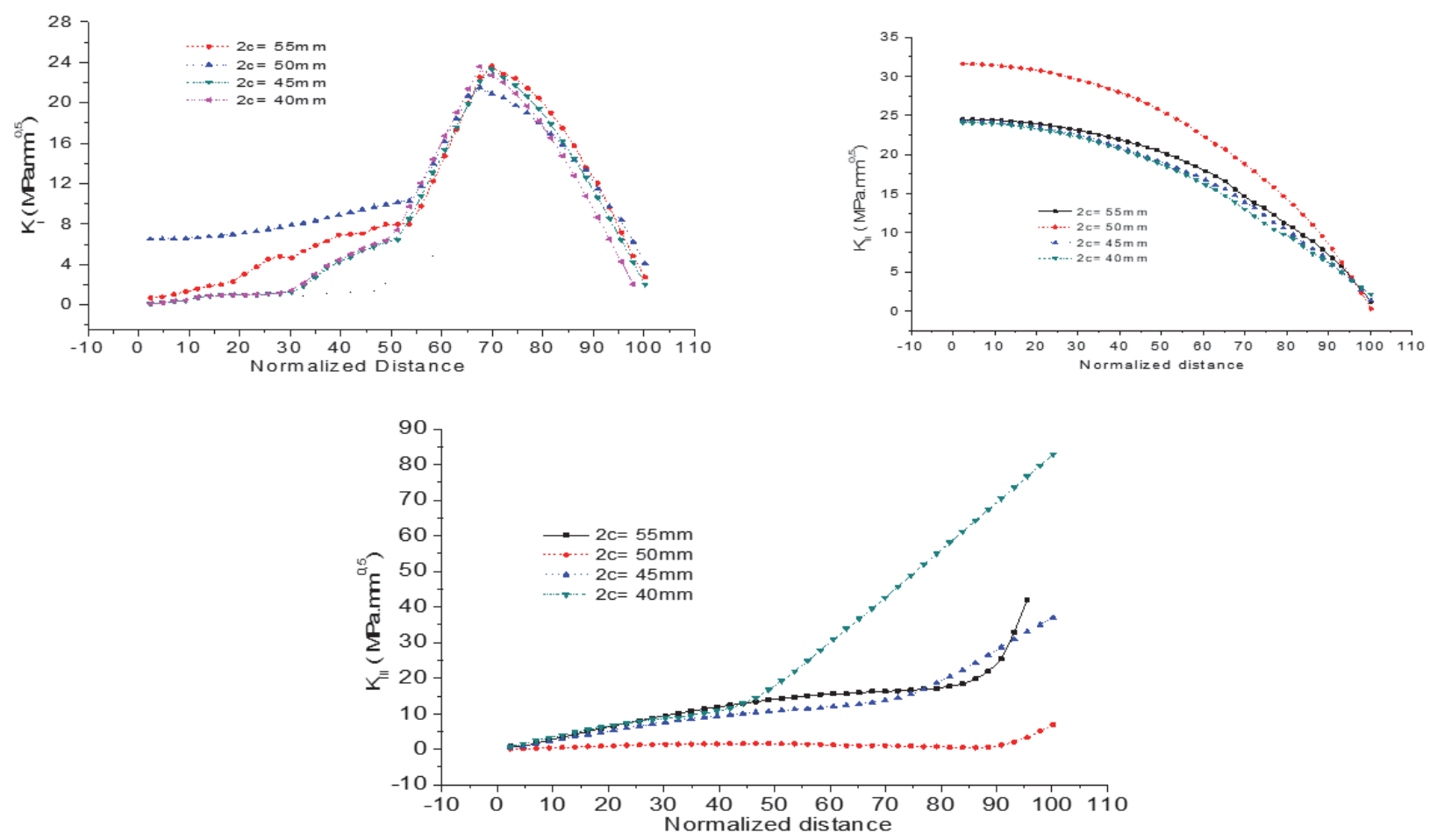

Figure 13: variation of the SIF: $\mathrm{K}_{\mathrm{I}}, \mathrm{K}_{\mathrm{II}}$ and $\mathrm{K}_{\mathrm{III}}$ along the crack front for different length. Repaired pipe with a $=7 \mathrm{~mm}$

A second analysis is presented in the following for a constant depth a $=7 \mathrm{~mm}$ and we change the length of the crack $2 \mathrm{c}$. In these results it was found that the three stress concentration factors keep almost the same behavior noticed for the depth a with respect to the crack length $2 \mathrm{c}$. The appearance of the $\mathrm{K}_{\mathrm{I}}$ shows the presence of three zones, the $K_{\mathrm{II}}$ is independent 
the length of the crack except for the length $2 \mathrm{c}=50 \mathrm{~mm}$, finally the $\mathrm{K}_{\mathrm{III}}$ proves its sensitivity to the longitudinal advancement of the crack always to the outer side of the crack which is in contact with the repair composite.

\section{C) Effect of crack shape:}

In this part the effect of the crack shape is expressed. It is important to note that the values of $\mathrm{K}_{\text {II }}$ and $\mathrm{K}_{\text {III }}$ are negligible compared to $\mathrm{K}_{\mathrm{I}}$ for a rectangular crack. Fig. 14 shows the variation of the $\mathrm{K}_{\mathrm{I}}$ for a rectangular crack and an elliptical crack along the fronts, it is clear that the rectangular crack marks a maximum higher than the elliptical crack; this is mainly due to the singularity of the rectangular crack, which has a $90^{\circ}$ angle (Hot point) that amplifies the stress. The presence of this singularity is confirmed by the appearance of $\mathrm{K}_{I}^{\max }$ at $65 \%$ of the normalized distance. In addition, the rectangular crack is governed only by mode 1 , while the semi elliptic crack knows the interaction of the three modes of fractures I, II and III .

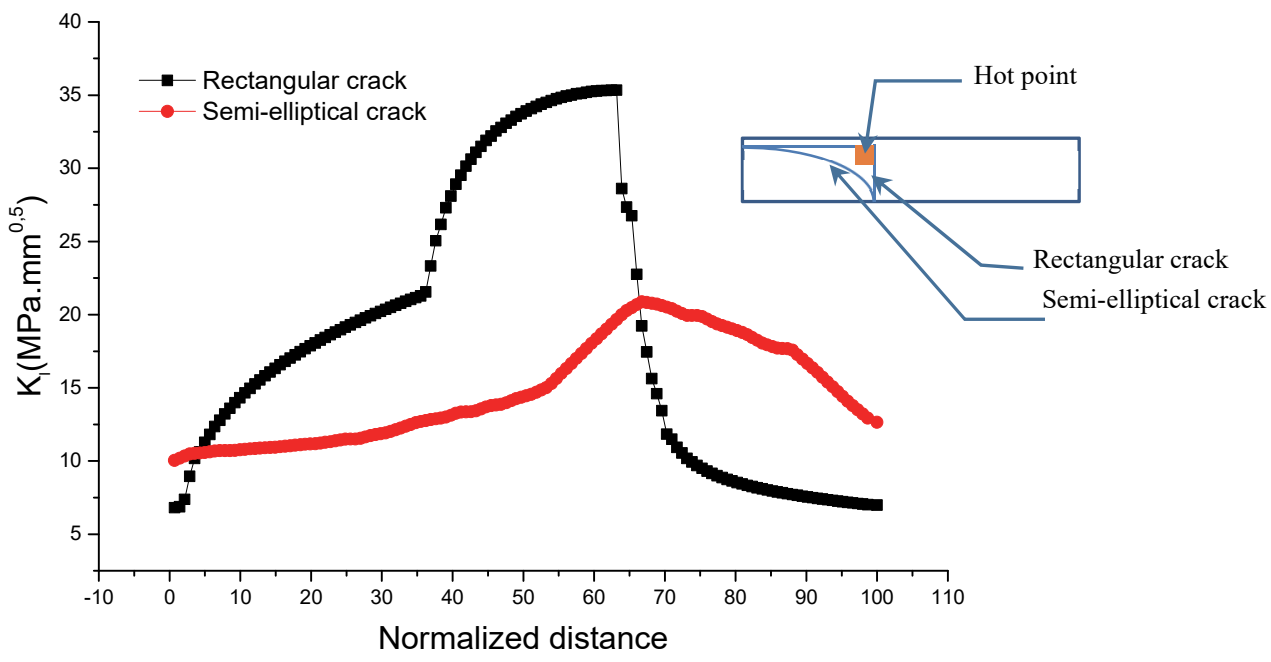

Figure 14: Variation of $\mathrm{K}_{\mathrm{I}}$ for rectangular and semi-elliptic crack of an unrepaired pipe $(2 \mathrm{c}=60 \mathrm{~mm}, \mathrm{a}=5 \mathrm{~mm})$

For composite repair, the distribution of the $\mathrm{K}_{\mathrm{I}}$ on the crack front is shown in Fig. 15, we can say that the composite repair is much more obvious for the rectangular crack than for the elliptical crack since we see that the repair brings the two curves to the same maximum $22 \mathrm{MPa} \mathrm{mm}{ }^{0.5}$ for mode I. It is concluded that the composite repair technique is effective for the two crack geometries studied.

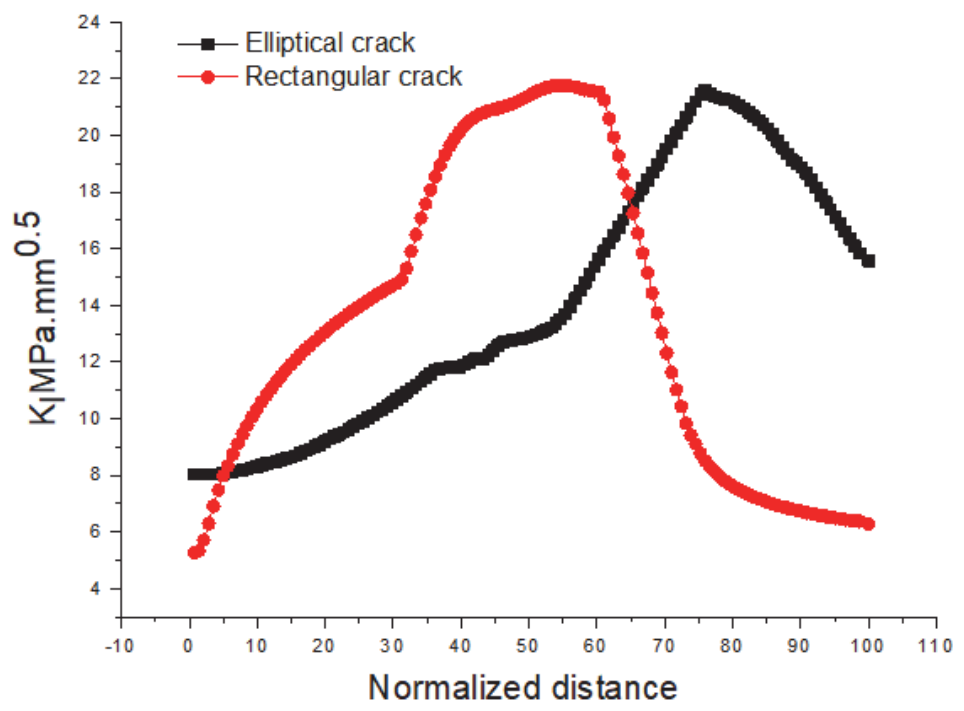

Figure 15: Variation of $K_{I}$ for rectangular and semi-elliptic crack of a repaired pipe $(2 \mathrm{c}=60 \mathrm{~mm}, a=5 \mathrm{~mm})$ 
D) Effect of composite thickness:

Fig. 16 shows the variation of the $\mathrm{K}_{\mathrm{I}}$ as a function of the thickness of the composite. The crack front describes a nonlinear behavior or one can distinguish four zones, to make out the effect of the thickness is drawn Fig. 17 which shows the variation of the $\mathrm{K}_{\mathrm{I}}$ for different thickness and for each zone.

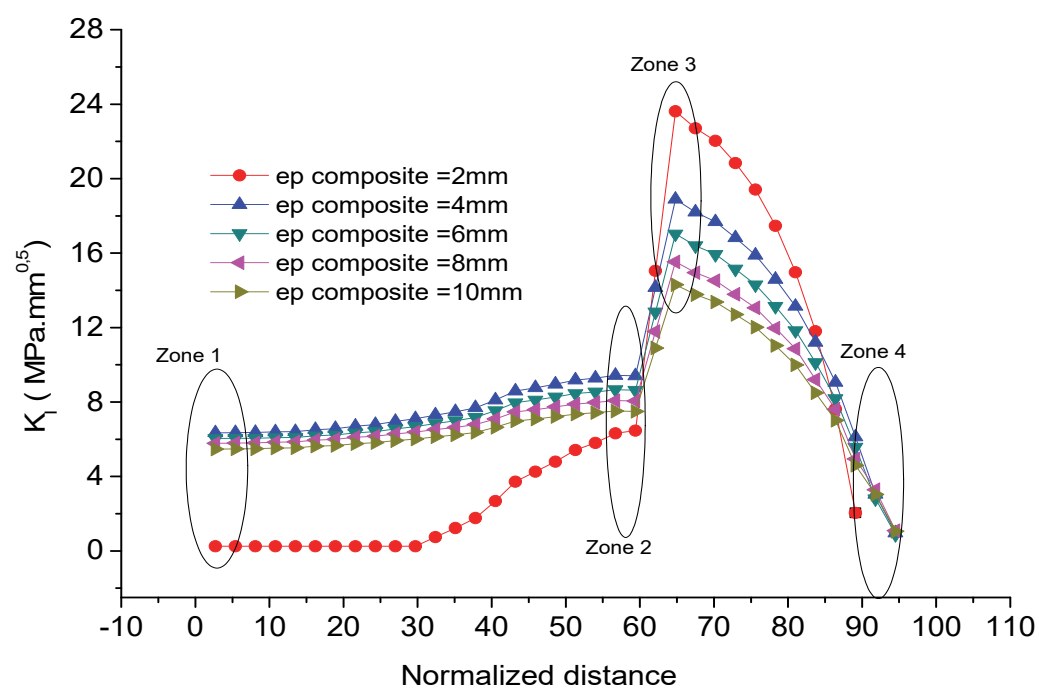

Figure 16: $\mathrm{K}_{\mathrm{I}}$ distribution along the front for different composite thickness. Repaired pipe $(2 \mathrm{c}=45 \mathrm{~mm}, \mathrm{a}=7 \mathrm{~mm})$.

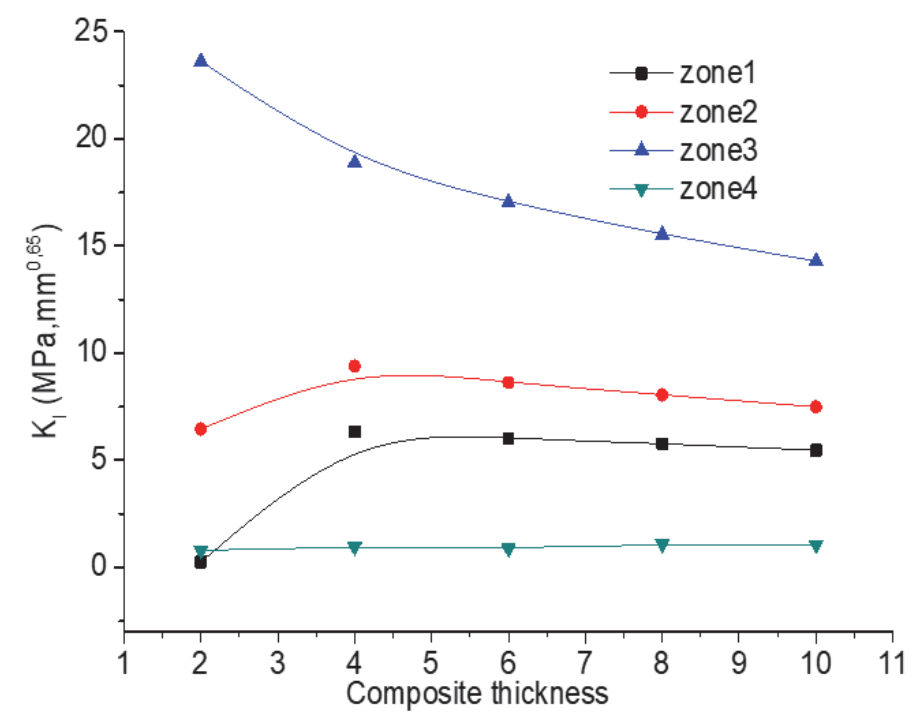

Figure 17: $\mathrm{K}_{\mathrm{I}}$ variation versus composite thickness for the four zones

It is clear from Fig. 17 that increasing the thickness of the patch leads to the decrease of the $\mathrm{K}_{\mathrm{I}}$ for internal and external crack positions. A thick patch allows a good absorption of the stresses, this is more marked for zone 3 whereas the $\mathrm{K}_{\mathrm{I}}$ tends to stabilize for zones 1 and 2 , for zone 4 the $\mathrm{K}_{\mathrm{I}}$ is independent of the thickness of the composite.

Fig. 18 (A) shows the $K_{I I}$ distribution along the front as a function of the thickness of the composite. For the $K_{I I}$ the behavior remains more intensive at the bottom of the crack and takes weak values towards the end of the crack, the effect of the thickness of the composite is significant only for bottom of the crack whereas it is independent of the limit of composite dimension crack. From Fig. 18 (B) it can be seen that in zone 1 the $K_{I I}$ reaches its maximum for a thickness of $4 \mathrm{~mm}$ from which it decreases. 

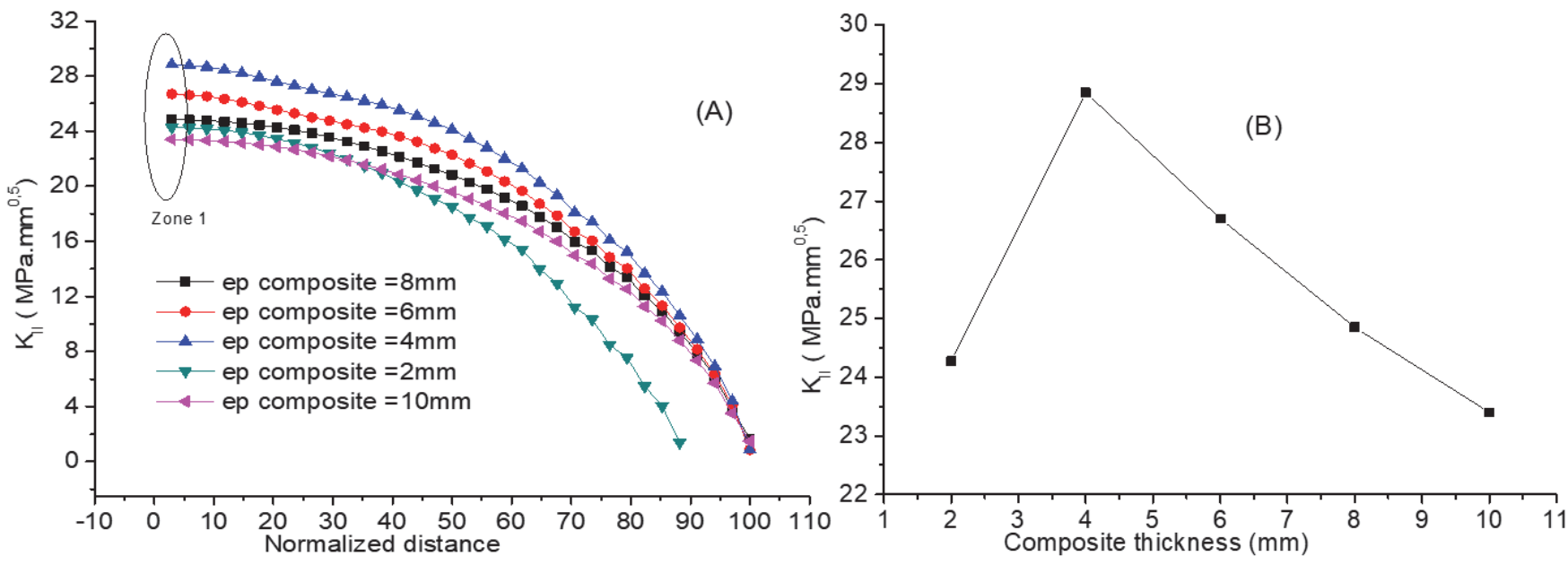

Figure 18: Distribution of the $\mathrm{K}_{\mathrm{II}}$ along the front for different thickness of the composite (A) variation of the $\mathrm{K}_{\mathrm{II}}$ as a function of the thickness of the composite $(B)$ - repaired pipe $(2 \mathrm{c}=45 \mathrm{~mm}, \mathrm{a}=7 \mathrm{~mm})$.
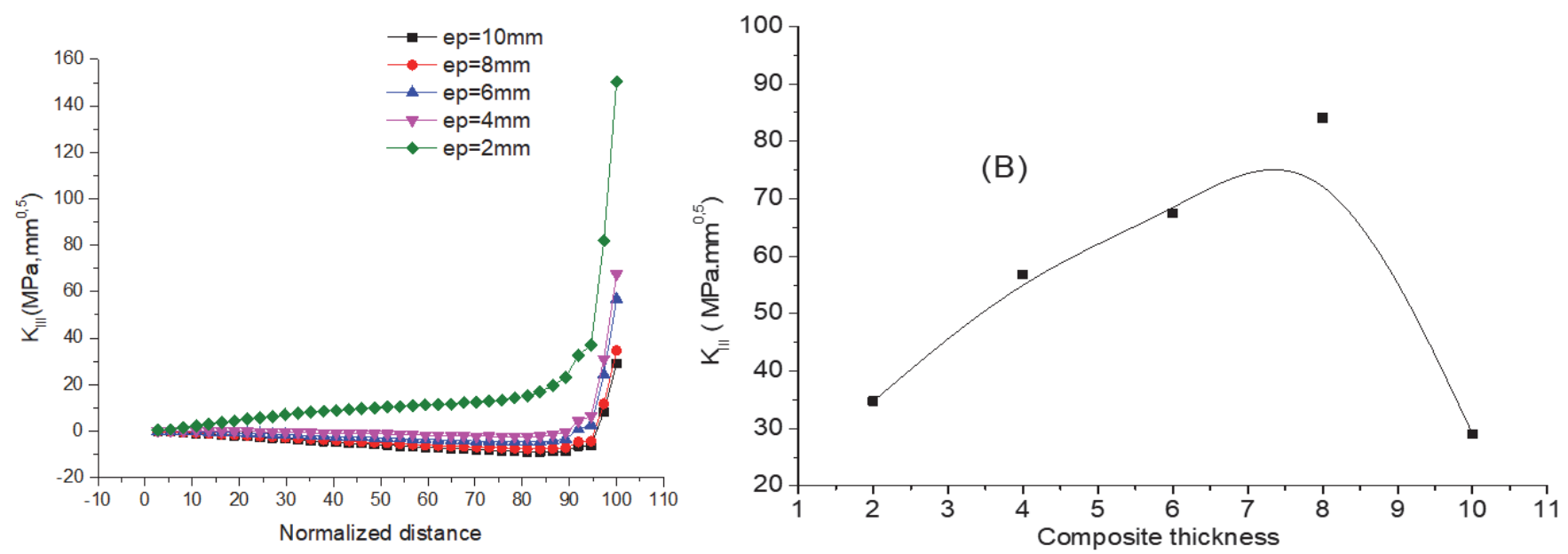

Figure 19: Distribution of the $K_{\text {III }}$ along the front for different thickness of the composite (A) variation of the $K_{I I}$ as a function of the thickness of the composite (B) - repaired pipe $(2 \mathrm{c}=45 \mathrm{~mm}, \mathrm{a}=7 \mathrm{~mm})$.

Fig. 19 (A) shows the distribution of $\mathrm{K}_{\text {III }}$ along the front as a function of the thickness of the composite. From this figure, it is noted that the mode III is not sensitive to the thickness of the composite at the bottom of the crack whereas it varies significantly with the thickness of the composite on the outer side of the crack or it is in direct contact with the patch, however it increases with the thickness of the composite up to a maximum value of $85 \mathrm{MPa} \cdot \mathrm{mm}^{0.5}$ for a value of $8 \mathrm{~mm}$, beyond this value the $\mathrm{K}_{\mathrm{III}}$ decreases and the patch resumes its role of absorption of constraints at the edge of the crack.

\section{E) Effect of the composite length:}

Fig. 20 describes the variation of the SIF as a function of the length of the composite patch along the crack front. It is observed that increasing the length of the patch does not reduce much the SIF. Except for the $\mathrm{K}_{\text {III, }}$ or it can be said that it is sensitive to increasing the length of the composite, the SIF in external position is reduced by $20 \%$. This result confirms that the choice of a long patch does not necessarily increase the effectiveness of the repair of the blow reduces the cost of the maintenance operation. 

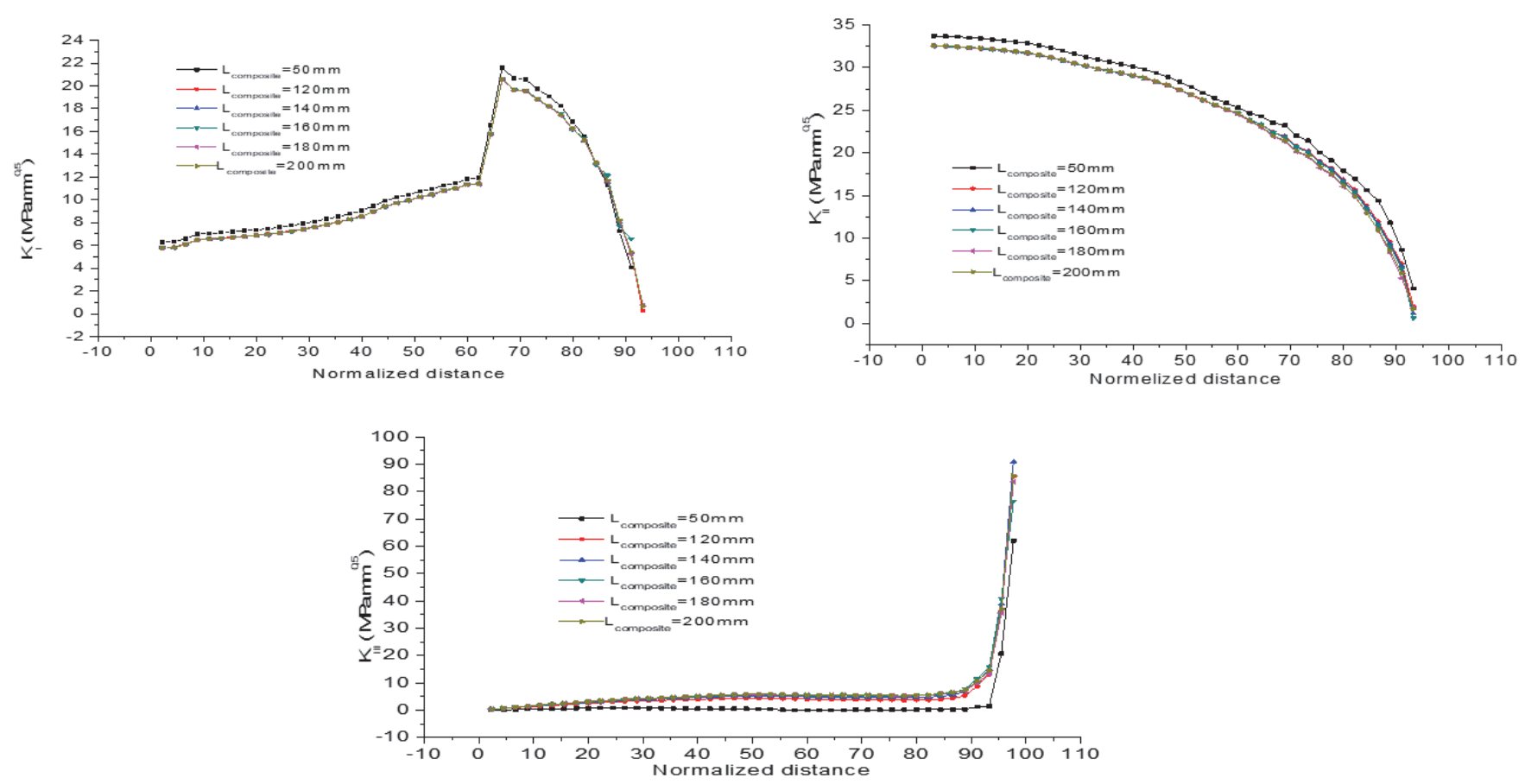

Figure 20: variation of the SIF: $\mathrm{K}_{\mathrm{I}}, \mathrm{K}_{\mathrm{II}}$ and $\mathrm{K}_{\mathrm{III}}$ along the crack front for different overwrap length. Repaired pipe with $2 \mathrm{c}=45 \mathrm{~mm}$, a $=$ $7 \mathrm{~mm}$.
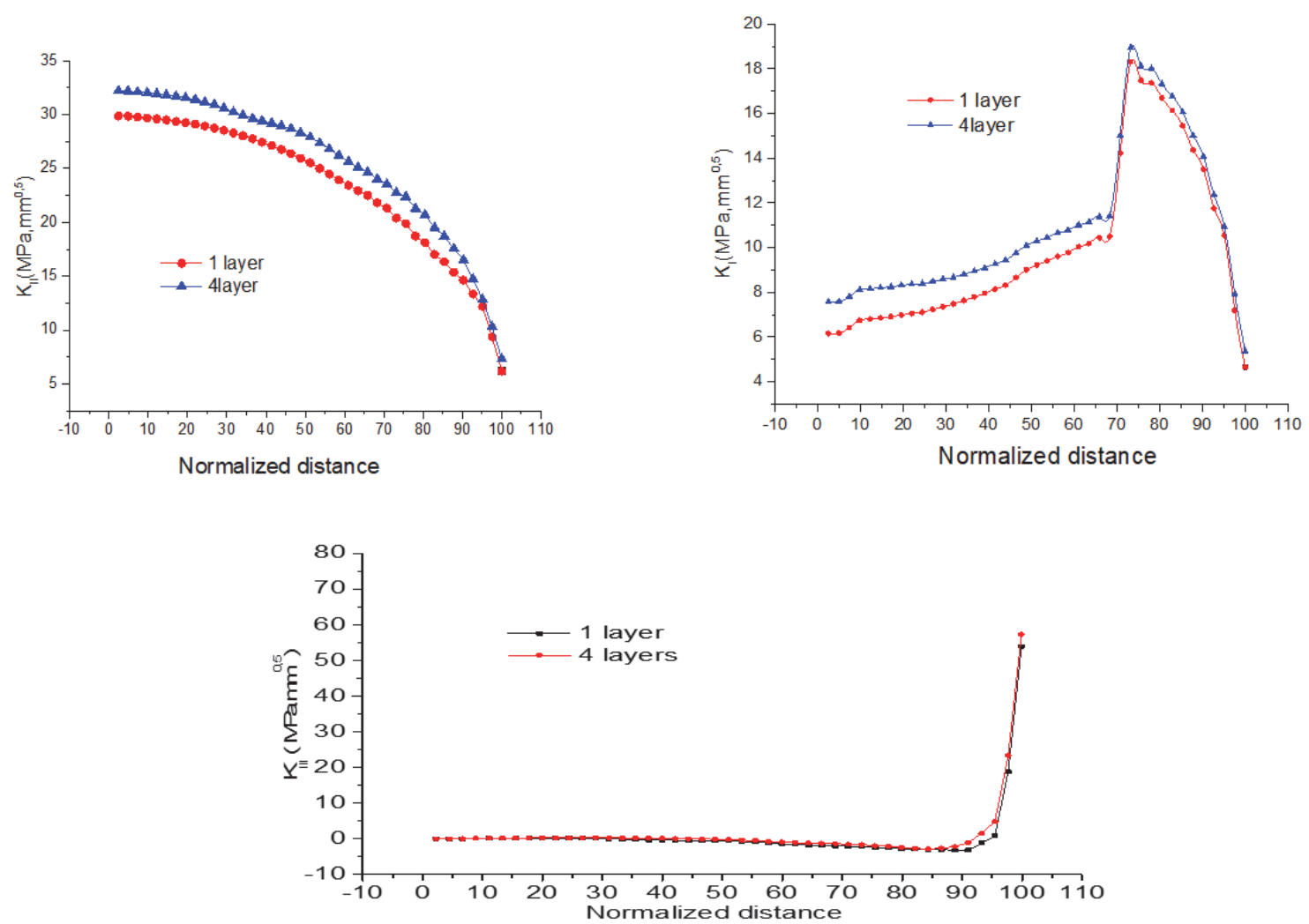

Figure 21: variation of $\mathrm{K}_{\mathrm{I}}, \mathrm{K}_{\mathrm{II}}$ and $\mathrm{K}_{\mathrm{III}}$ along the crack front for a single layer of composite and for four sub-layers of the composite. Repaired pipe with $(2 \mathrm{c}=60 \mathrm{~mm}, \mathrm{a}=7 \mathrm{~mm})$. 


\section{F) Effect of the repair method:}

In reality, the composite does not have a single thickness but is wound around the pipeline by several layers. By taking this evidence we have assumed two repair configurations, at first, we consider a single layer of a composite of $4 \mathrm{~mm}$ thick, the second, we apply a repair with four (4) layers of composite and four (4) layers of adhesives to the same thickness. Fig. 21 shows the distribution of SIF along the front of cracks, it is clear that the two configurations do not present a big difference for the three modes. This result presents an excellent agreement with those of M. M. Benziane et al[29]

\section{CONCLUSION}

7 he results obtained numerically by the three-dimensional finite element method enable us to draw the following conclusions:

1 . We note the presence of three failure modes along the semi elliptical crack front. The maximum value of the SIF along the crack tip is that of the mode $\mathrm{K}_{\mathrm{II}} .75 \%$ of the crack front is influenced by the mode II, $20 \%$ by mode I and only $5 \%$ of the crack front is commanded by the mode III.

2. For longitudinal elliptical cracks the risk of rupture of pipelines is more dangerous on the internal fronts than for external ones.

3. The repair on the external side is better with an efficiency of $81 \%$ for the mode III. This is mainly due to the direct contact of the lips of the crack with the composite which ensures a good transfer of the concentrations of the constraints of the pipe through the adhesive to the composite.

4. The composite repair technique is effective for the two crack geometries studied.

5. the rectangular crack is governed only by mode 1 , while the semi elliptic crack knows the interaction of the three modes of fractures I, II and III.

6. The reduction of stress intensity factor by the composite patch leads us to conclude that the fatigue life can be improved. 7. The increase of the thickness of the patch leads to the decrease of the SIF for the internal and external crack positions. A thick patch allows a good absorption of the constraints.

8. It is necessary to optimize the characteristic and geometric (thickness, length) of the composite to have an effective repair. This can lead to low cost repair and hence decrease the cost of energy.

9. The use of a layer of composite or the decomposed in several layers to simulate the real case showed that there is not a big difference compared to our results. This confirms that only the first layer of the composite which absorb the maximum stress of the pipe.

\section{REFERENCES}

[1] Mohitpour, M., Golshan, H., Murray, A. (2003). Pipeline design and construction: a practical approach. 2nd ed. New York, NY: ASME Press; 2003. pp. 499-518.

[2] Chapetti M.D., Otegaui, J.L., Manfredi, C., Martins, C.F. (2001). Full scale experimental analysis of stress states in sleeve repairs of gas pipelines. International Journal of Pressure Vessels and Piping, 78, pp. 379-87.

[3] Koch GH, Brongers MP, Tompson NG, Virmani YP, Payer JH. (2001). Corrosion cost and preventative strategies in the United States. Federal Highway Administration, Office of Infrastructure Research and Development, pp. 260-311.

[4] Matheas, J.D. (2005). Etude du comportement mécanique de patchs composites utilisés pour le renforcement de structures métalliques aéronautiques. pp. 13-21. PhD thesis. N d'ordre : D.U. 1587 EDSPIC : 323.

[5] Andrew, J., Patrick., composites- case studies of pipeline repair applications, Clock Spring Company, L.P., Huntingdon, $\mathrm{UK}$.

[6] ASME B31.4. (2003). Liquid transportation system for hydrocarbons, liquid petroleum gas, anhydrous ammonia and alcohols. New York: American Society of Mechanical Engineers; 2003.

[7] ASME B31.8. (2003). Gas transmission and distribution piping systems. New York: American Society of Mechanical Engineers; 2003.

[8] Alexander, C.R., Francini, R. (2006). State of the art assessment of composite systems used to repair transmission pipelines. Paper no. IPC2006-10484. In: Proceedings of the 16th international pipeline conference, Calgary, Canada September. pp. 25-29. 
[9] Newman, J.C., J.r. and Raju, I.S. (1983). Stress Intensity Factor Equations for Cracks in Three Dimensional Finite Bodies. Fracture Mechanics: Fourteenth Symposium_-Volume I: Theory and Analysis, ASTM STP 791, J. C. Lewis and G. Sines, Eds. American Society for Testing and Materials. pp. I-238 - I-265.

[10] A. Saffih, S. Hariri. (2006). Numerical study of elliptical cracks in cylinders with a thickness transition, International Journal of Pressure Vessels and Piping. 83. pp. 35-41.

[11] Gosz, M. and Moran, B. (1997). Stress-intensity factors along three-dimensional elliptical crack fronts, Office of Aviation Research Washington, D.C. 20591-DOT/FAA/AR-96/97.

[12] Khoramishad, H. and Ayatollahi, M. R. (2009). Finite element analysis of a semi-elliptical external crack in a Buried pipe. Transactions of the Canadian Society for Mechanical Engineering, Vol. 33, No. 3, 2009

[13] Rooke, D.P. \& Cartwright, D.J. (1976). Compendium of stress intensity factors. HMSO Ministry of Defence. Procurement Executive.

[14] Heliot, J., Labbens, R.C., Pelissier-Tanon, A. (1979). Semi elliptical cracks in a cylinder subjected to stress gradient. Am Soc Test Mater. pp. 341-64.

[15] McGowan, J.J., Raymund M. (1979). Stress intensity factor solutions for internal longitudinal semi-elliptical surface flaws in a cylinder under arbitrary loadings. Am Soc Test Mater. pp. 365-80.

[16] RSEM. (1997). Rules for in service inspection on nuclear power plant components. AFCEN, Tour Framatome, F92084 Paris La défense Cedex; Edition .

[17] Chapuliot, S., Lacire, M.H. (1998). Stress intensity factors for internal circumferential cracks in tubes over a wide range of radius over thickness ratios. Proceedings of the ASME PVP Conference, vol. 365; 1998. pp. 95-106.

[18] Chapuliot, S., Lacire, M.H. (1999). Stress intensity factors for external circumferential cracks in tubes over a wide range of radius over thickness ratios. Proceedings of the ASME PVP Conference, vol. 388; 1999. pp. 3-12.

[19] Meneghetti, G., Campagnolo, A., Avalle, M., Castagnetti, D., Colussi, M., Corigliano, P., De Agostinis, M., Dragoni, E., Fontanari, V., Frendo, F., Goglio, L., Marannano, G., Marulo, G., Moroni, F., Pantano, A., Rebora, A., Scattina, A., Spaggiari, A., Zuccarello, B. (2018). Rapid evaluation of notch stress intensity factors using the peak stress method: Comparison of commercial finite element codes for a range of mesh patterns, Fatigue Fract. Eng. Mater. Struct., 41(5), Doi: $10.1111 /$ ffe.12751.

[20] Campagnolo, A., Meneghetti, G. (2018). Rapid estimation of notch stress intensity factors in 3D large-scale welded structures using the peak stress method, MATEC Web Conf., 165, Doi: 10.1051/matecconf/201816517004.

[21] API 5L. Specification for line pipe. APL specification 5L, 42nd ed. USA: The American Petroleum Institute; 2000.

[22] Walker, A.C., Williams, K.A.J. (1995). Strain based design of pipelines. In: Proceedings of the ASME 14th international conference on ocean, offshore and arctic engineering, vol. V, Copenhagen, Denmark; 1995. pp. 345-50.

[23] Hyer, M.W. (2008). Stress analysis of fiber-reinforced composite materials. New York (USA): McGraw-Hill; 2008.

[24] Dassault Systèmes Simulia Corp - Abaqus/CAE 6.14 User's Manual.

[25] Dake, Y., Sridhar, I., Zhongmin, X., Kumar, S.B. (2012). Fracture capacity of girth weldedpipelines with 3D surface cracks subjected to biaxial loading conditions. Int JPress Vessels Pip. pp. 92-115.

[26] Anderson, T.L. (2005). Fracture mechanics: fundamentals and applications 3rd edition,CRC Press; 2005.

[27] Mcmeeking, R.C., Parks, D.M. (1979). On criteria for J-dominance of crack tip fields in large-scale yielding. Philadelphia: ASTM STP 668; 1979. pp. 175e194

[28] Bezzerrouki, M., Albedah, A., Bachir Bouiadjra, B., Ouddad, W., Benyahia, F. (2011). Computation of the stress intensity factor for repaired cracks with bonded composite wrap in pipes under traction effect. Journal of Thermoplastic Composite Materials. DOI: 10.1177/0892705711430428.

[29] Madjid Meriem-Benziane , Sabah, A., Wahab, A., Hamou, Z., Benoauda, B., Mohamed, H.M., Guy, P. (2015). Finite element analysis of the integrity of an API X65 pipeline with a longitudinal crack repaired with single- and doublebonded composites. Composites Part B 77 . pp. 431-439 